Revista IBERC

v. 4, n. 1, p. 133-153, jan./abr. 2021

www.responsabilidadecivil.org/revista-iberc

DOI: https://doi.org/10.37963/iberc.v3i2.150

\title{
O DANO MORAL IN RE IPSA E O TRATAMENTO INDEVIDO DE DADOS SOB O PRISMA DOS JULGADOS: RESP. 1.758.799/MG E ADI 6387 MC-REF
}

\author{
MORAL DAMAGE IN RE IPSA AND DUE PROCESSING OF DATA UNDER THE PRISM OF \\ THE JUDGES: RESP. 1,758,799 / MG AND ADI 6387 MC-REF
}

João Victor Gontijo Cardoso i

RESUMO: A sociedade da informação alterou incisivamente na forma das pessoas se relacionarem, influenciada diretamente pelo advento da Internet. O referido ambiente é responsável por armazenar inúmeras informações dos usuários, já que é nele que as pessoas se conectam e passam a maior parte do tempo. Nesse contexto, com a Lei Geral de Proteção de Dados, a ciência jurídica começa a adentrar neste fresco terreno tecnológico, com a finalidade de tutelar os informes pessoais dos sujeitos de direito, principalmente a privacidade, com fim de minimizar sua vulnerabilidade perante os agentes econômicos. Portanto, neste cenário, é imprescindível que o instituto da responsabilidade civil esteja bem delineado quando se fala tratamento indevido de dados. Assim, este trabalho, a partir do método dedutivo, buscará demonstrar que o dano moral causado pelos tratadores de dados é presumido, tendo como meio a base da pesquisa bibliográfica e julgados dos tribunais. O resultado alcançado é que havendo violação de direitos fundamentais, subsistirá o dano moral in re ipsa.

Palavras-chave: Responsabilidade Civil. Privacidade. Sigilo de dados. Tratamento de Dados. Dano Moral in re ipsa.

\begin{abstract}
The information society has sharply changed the way people relate, directly influenced by the advent of the Internet. This environment is responsible for storing users' information, since it is there that people connect and spend most of their time. In this context, with the General Data Protection Law, legal science begins to enter this fresh technological terrain, with the protection of personal information about the rights of law, especially privacy, in order to minimize their vulnerability to law enforcement officers. Therefore, in this scenario, it is essential that the civil liability institute is well defined when it comes to improper data processing. Thus, this work, based on the deductive method, will seek to demonstrate that the moral damage manifested by data controllers is presumed, using the basis of bibliographic research and judgments from the courts. The result is that if there is a violation of fundamental rights, moral damage will continue in re ipsa.
\end{abstract}

Keywords: Civil responsability. Privacy. Data confidentiality. Data Processing. Moral Damage in re ipsa.

SUMARIO: 1. Introdução. 2. A sociedade e a tecnologia. 2.1 A quarta revolução industrial e o tratamento de dados. 2.2. Casos celebres sobre o tratamento indevido de dados. 3. Direitos da Personalidade. 3.1 Privacidade: intimidade e sigilo. 4. Considerações sobre a responsabilidade civil. 4.1 Responsabilidade civil:

\footnotetext{
i Graduação em Direito pela PUC-MG. Tem experiência no Direito Privado, com foco no Direito Cível, em que atuou como monitor de Direito Civil I - Obrigações e Direito Civil II - Responsabilidade Extracontratual e Teoria Geral dos Contratos na PUC-MG, participante do PICV-2019 da PUC-MG com o tema: Dano existencial e as Pessoas Jurídicas, também é bolsista do CNPq através do PIBIC 2019, com a pesquisa: Danos Existenciais e as Pessoas Jurídicas de Direito Público: o caso de Brumadinho. https://orcid.org/0000-0003-3335-9485.
} 
contratual e extracontratual. 4.2 Responsabilidade civil subjetiva ou objetiva. 4.3 Dano Mora in re ipsa. 5. Considerações finais. Referências.

\section{INTRODUÇÃO}

O implemento da tecnologia evolucionou a forma de relacionamento, a distância deixou de ser empecilho para que houvesse comunicação entre pessoas, principalmente a partir do advento das redes sociais. Em consequência a informação o conhecimento passaram a ser mais acessíveis.

O lado negativo desta evolução, é que o indivíduo passou a armazenar informações relativas a sua privacidade no mundo virtualizado, se tornando cada vez mais vulnerável. Essas informações passaram a ser objeto de interesse do mercado econômico.

Nesse sentido, o presente trabalho visou abordar um dos temas que se tornou gritante no mundo digital, principalmente após a disseminação midiática de casos celebres que envolve tratamento irregular dos dados pessoais.

A internet que deveria ser utilizada para benefício dos indivíduos passou a ser ambiente para cometimento de crimes cibernéticos e se valer como instrumento para violar direitos. Além disso, havia uma dificuldade da via legislativa em acompanhar o avanço tecnológico, implicando, por consequência, que a internet tonasse um lugar desconhecido, onde não há lei não há ilegalidade.

Direitos fundamentais e direitos da personalidade, sobretudo, privacidade e intimidade, tão valiosos, passaram a ser diretamente ofendidos.

As linhas que se seguem se dividem em três tópicos, o primeiro busca ilustrar a sociedade da informação, expondo os elementos e a forma de funcionamento da quarta revolução industrial, além de exemplificar o tratamento irregular de dados com casos celebres. $O$ segundo abordará os direitos da personalidade e constitucionais, especificando na privacidade, intimidade e sigilo de dados. O terceiro se propõe a analisar a Lei Geral de Proteção de Dados, demonstrando que o tratamento irregular de dados pessoais e sensíveis pode ser lesivo aos direitos da personalidade de seu titular, e, em decorrência, traçando reflexões sobre a aplicação da responsabilidade civil e a possibilidade da configuração do dano moral presumido.

\section{A SOCIEDADE E A TECNOLOGIA}

Sobre um aspecto sociológico a globalização e a tecnologia marcam o século XXI, alterando a forma das pessoas se relacionarem e fomentando a busca pela informação. Conforme ensina Eduardo Bittar sobre as relações atuais "[...] transmuta o foco das relações de comunicação inter praesentes para relações de comunicação inter absentes." ${ }^{1}$ Este prelúdio caracteriza a sociedade inserida na tecnologia, a denominada sociedade da informação.

${ }^{1}$ BITTAR, Eduardo C. B. Curso de filosofia do direito. 14. ed. Rio de Janeiro: Atlas, 2019, p. 831. 
O mundo pós-moderno possui como características a informação rápida, conhecimento nas palmas das mãos, globalização, tecnologia e internet. O sociólogo Zygmunt Bauman aponta que essa sociedade habita um mundo líquido "[...] porque, como todos os líquidos, ele jamais se imobiliza nem conserva sua forma por muito tempo. Tudo ou quase tudo em nosso mundo está sempre em mudança." 2

Esta mudança no modo de se relacionar foi diretamente influenciado pela internet, que é uma rede de extensão ilimitada, e redes, por sua vez, é algo que é responsável por interligar as coisas ou pessoas.

A internet por ter uma extensão ilimitada traz diversas benesses aos usuários, contudo, traz malefícios, principalmente, em relação a privacidade. Em apertada síntese, cita-se Eduardo Bittar que elenca os pontos negativos, especificamente no que concerne à privacidade do sujeito de direito:

[...] (d) torna a privacidade e a informação as mercadorias de um tempo; [...] (f) cria a disputa, desestabilizadora de governos, pelos "pacotes de informações", um campo de guerra entre o "detentor da informação" e o "chantageado da era da informação"; $(\mathrm{g})$ aumenta o grau de insegurança na administração, posse e circulação da informação, onde o roubo de dados, a hackerização de programas e a insegurança tecnológica aparecem como constantes ameaças; [...] (j) redefine a fronteira da privacidade, nos termos de novas aproximações de violações a direitos e liberdades; [...] (n) cria o tráfico de dados e informações, a ciber-criminalidade com finalidades danosas, invasivas e delituosas, aí incluindo a extorsão pela posse de informações desvantajosas; $[\ldots]^{3}$

Percebe-se que esta mudança social de convivência para o mundo virtualizado, fragiliza potencialmente a privacidade, uma vez que a inclusão digital exige informações pessoais dos usuários para utilização dos serviços ou aquisição de produtos, além de ser uma forma de vedar o anonimato.

Esse conjunto de informações sobre as pessoas são denominados de dados, que por sua vez são armazenados em uma base. Com fito de diminuir a vulnerabilidade dos internautas, esta grande base de informações merece proteção dos tratadores.

Fato é, a internet se tornou algo indispensável no cotidiano das pessoas, não obstante, cogita-se elencar o livro acesso a internet no rol dos direitos fundamentais.

Entrementes, este ambiente cibernético, deve ao menos, oferecer mínima segurança aos usuários. Sobretudo, na proteção dos dados, pois neles estão contidas informações sobre a privacidade e intimidade dos sujeitos de direito.

Como bem lembra o jurista Stefano Rodotà, nas últimas décadas, vivenciamos um verdadeiro "processo de inexorável reinvenção da privacidade." ${ }^{\prime} \mathrm{O}$ fenômeno de virtualização das relações humanas parece que está no início, portanto, a proteção e a repressão ao tratamento indevido de dados devem ser aprofundadas.

\footnotetext{
2 BAUMAN, Zygmunt. 44 cartas do mundo líquido moderno. Rio de Janeiro: Zahar, 2011, p. 7.

3 BITTAR, Eduardo C. B. Curso de filosofia do direito. 14. ed. Rio de Janeiro: Atlas, 2019, p. 833.

${ }^{4}$ RODOTÀ, Stefano. A vida na sociedade da vigilância: a privacidade hoje. Rio de Janeiro: Renovar, 2008, p. 15.
} 


\subsection{A quarta revolução industrial e o tratamento de dados}

A quarta revolução industrial é responsável pela implementação tecnológica e virtualização das relações humanas, não obstante, o mundo vê surgir o fenômeno da digitalização, suas características consistem na onipresença de máquinas, computadores, notebooks, tablets e smartphones, livros digitais, conexão à internet e convergência da comunicação para o formato digital (Facebook, Instagram, Twitter, Telegram, Whatsapp, Microsoft Teams, Zoom etc.).

Diante disso, os autores Hofmann e Rusch entendem que:

[...] a Quarta Revolução Industrial pode ser melhor descrita como uma mudança na lógica de fabricação para uma abordagem de valor cada vez mais descentralizada e auto-reguladora, habilitada por conceitos e tecnologias como CPS, IoT, IOS, computação em nuvem ou manufatura aditiva e fábricas inteligentes, de modo a ajudar as empresas a atender a produção futura requisitos. ${ }^{5}$

Nesse contexto, o mundo se prepara para uma nova geração de pessoas, os denominados nativos digitais, isto é, aqueles que nascem inseridos na tecnologia, para tanto, o mercado também se prepara e são traçadas estratégias de marketing fundadas em análises de grandes bases de dados que contém informações sobre os consumidores.

Não obstante, esta ingerência tecnológica alterou modelos de negócios tradicionais, criando novos, cita-se a Netflix na locação de filmes, a Uber no transporte urbano, o ifood no delivery, a Booking na hospedagem, os bancos e corretoras digitais no sistema financeiro, a Amazon no varejo, entre outros.

$\mathrm{Na}$ ciência jurídica, em específico no direito civil é fácil constatar esta mudança, o aumento exponencial de contratos entre ausentes (art. 434 do Código Civil) se dá em decorrência dos chamados contratos eletrônicos, os juristas Nelson Rosenvald e Cristiano Chaves de Farias, apontam que estes contratos sofrem o fenômeno da despersonalização, que dificulta a aferição de vício de consentimento do negócio jurídico, vejamos: "[...] no momento da celebração, em que são transmitidas as declarações de vontade, não estão presentes os seres humanos a quem são atribuíveis, mas sim computadores que se comunicam diretamente entre si." ${ }^{6}$. Além deste elemento, tem-se a desmaterialização do contrato:

Ele é concluído sem forma física. São bits e códigos binários. Isto cria problemas quanto à prova da contratação, ou mesmo de seu conteúdo e momento. Muitas vezes, o próprio objeto do contrato é imaterial, assim o vício do objeto é informacional [...] Ademais, o comércio eletrônico atualiza a noção de objeto, pois as prestações contratuais dos contratos informáticos são imateriais, como o fornecimento de software, jogos, filmes e músicas. ${ }^{7}$

\footnotetext{
${ }^{5}$ HOFMANN, E.; RÜSCH, M. Industry 4.0 and the current status as well as future prospects on logistics. Computers in Industry, v. 89, p. 23-34, 2017, p. 25

${ }^{6}$ ROSENVALD, Nelson; FARIAS, Cristiano Chaves de. Curso de Direito Civil: contratos. 7. ed. rev. atual. Salvador: JusPodivm, 2017a, p. 364.

7 ROSENVALD, Nelson; FARIAS, Cristiano Chaves. Curso de Direito Civil: contratos. 7. Ed. rev. atual. Salvador: JusPodivm, 2017a, p. 365.
} 
Neste ínterim, os crimes cibernéticos ganham espaço, há uma necessidade de readaptação na ótica da punibilidade, motivo pelo qual criou-se a Lei Carolina Dieckmann, com fim punir as invasões no espaço virtual. Isto porque, por trás desta indústria há um mercado lucrativo em relação aos roubos de dados.

A empresa Facebook S.A adota um programa chamado de bug bounty que recompensa monetariamente hackers por tentarem encontrar falhas na segurança do serviço prestado, encontrada as falhas, blinda-se de outros invasores digitais, os chamados crackers. Neste mesmo sentido, obtempera Paulo de Almeida:

A Indústria 4.0 necessita de proteção contra possíveis ataques de hackers, que podem comprometer o desempenho da empresa no que concerne à fabricação de produtos, além do risco de invasão e alteração/apropriação das informações sobre os clientes. ${ }^{8}$

Dito isso, é preciso contextualizar e conceituar os elementos basilares e estruturantes desta nova realidade social. "São considerados elementos base para a Indústria 4.0 sistemas ciber físicos, internet das coisas (IoT) e internet de serviços (loS)." ${ }^{9}$ Para tanto, necessita-se conceituar cada elemento base, vejamos:

\begin{abstract}
- Os CPS são sistemas mecatrônicos compostos por sensores e atuadores, controlados por software que, monitorando uma série de dados, supervisionam e controlam processos industriais mecânicos, químicos, térmicos ou elétricos, no campo físico [...] Esses sistemas ciber físicos transmitem informações e dados em tempo real, conectados, por meio do espaço cibernético, mundo virtual para o mundo real.

- loT [...] chamamos objetos inteligentes, ou smart products, quando a coisa, ou o objeto, passa a ter capacidade de processamento juntamente com a capacidade de conexão com a internet. [...] Geladeiras inteligentes poderão elaborar a lista dos itens faltantes, consultar mercados que tragam melhores relações custo-benefício, enviar a lista de compras já com os preços e condições de pagamento para a sua autorização, e uma vez autorizado, fechar o pedido de compra, para entrega no dia e horário da sua maior conveniência pessoal.

- Internet of services, ou abreviadamente loS. Pela loS, novos serviços são disponibilizados por meio da internet ou internamente à empresa. Você poderá ser alertado pelo celular/tablet ou computador que o seu carro precisa de revisão e/ou que chegou o período de trocar os pneus. ${ }^{10}$
\end{abstract}

Na sociedade da informação, a tecnologia se manifesta nos produtos e serviços que são desenvolvidos com fulcro em uma base de dados, que armazena os mais diversos perfis dos consumidores. Este método é utilizado para que haja um maior direcionamento dos produtos e serviços aumentando o consumo, evitando-se o desperdício.

Em relação aos elementos estruturantes, pode-se dizer que é neles que residem a maior preocupação quando se fala em danos causados em decorrência do tratamento irregular de dados, pode-se lista-los em:

${ }^{8}$ ALMEIDA, Paulo Samuel de. Indústria 4.0: princípios básicos, aplicabilidade e implantação na área industrial. São Paulo: Érica, 2019, p. 66.

${ }^{9}$ SACOMANO, Jose Benedito; et. al. Indústria 4.0: conceitos e fundamentos. São Paulo: Blucher, 2018, p. 34.

10 SACOMANO, Jose Benedito; et. al. Indústria 4.0: conceitos e fundamentos. São Paulo: Blucher, 2018, p. 34-36. 
- A Automação é definida como a realização de tarefas sem a intervenção humana, com equipamentos que funcionam sozinhos e possuem a capacidade de controlar a si próprios [...] O uso de robôs tem especial importância em tarefas que apresentam risco ao trabalhador, exigem grande velocidade e/ou precisão de execução, sejam atividades extenuantes ou repetitivas.

- Machine to Machine pode ser definido como a comunicação entre duas máquinas ou a transferência de dados de um dispositivo a um computador central que pode ser realizada por meio de rede com ou sem fio, por meio de cabos, bluetooth, rede de telefonia celular ou internet.

- Inteligência artificial é utilizar dispositivos ou métodos computacionais de forma similar à capacidade de raciocínio do ser humano, resolvendo problemas da maneira mais eficiente possível.

- Big data a massa de informações geradas por todo sistema, seja ele produtivo, comercial, marketing e outros, que precisa ser bem analisada, pois há riquezas de detalhes que podem significar o sucesso de qualquer empresa.

- Computação em nuvem assim chamada por não se saber onde estão localizados os servidores que armazenam e processam dados, assim como não se sabe por onde passam estes dados, nem onde os dados são replicados [...] A computação em nuvem é fundamental para que as informações e dados possam ser acessadas, de forma fácil, de qualquer parte do mundo em que haja internet.

- Segurança cibernética Como todas as informações, dados e comandos trafegam online, é importante que haja segurança contra invasões às redes de internet ou Intranet. O vazamento ou roubo dos dados e informações, ou a entrada de elementos maliciosos na rede, comprometem todo modelo da Indústria 4.0, sendo que ainda há muito a fazer para tornar a internet segura. ${ }^{11}$

Percebe-se que em todos os elementos estruturantes da indústria 4.0, tem-se o tratamento de dados, que pode ser conceituado pela Lei 13.709/2018 que dispõe sobre a Lei Geral de Proteção de Dados Pessoais:

Art. $5^{\circ}$ Para os fins desta Lei, considera-se:

$X$ - Tratamento: toda operação realizada com dados pessoais, como as que se referem a coleta, produção, recepção, classificação, utilização, acesso, reprodução, transmissão, distribuição, processamento, arquivamento, armazenamento, eliminação, avaliação ou controle da informação, modificação, comunicação, transferência, difusão ou extração; ${ }^{12}$

Trata-se de uma norma jurídica com várias condutas ou plurinucleares, e é daí que nasce a responsabilidade civil, como bem lembra José de Aguiar Dias: "toda manifestação da atividade humana traz em si o problema da responsabilidade."13

Dessa forma, qualquer conduta tipificada nesta norma jurídica, que não observada, causará potencialmente um dano ao titular dos dados.

\subsection{Casos célebres sobre o tratamento irregular de dados}

Preliminarmente é imperioso destacar o conceito legal de dados, para tanto, o artigo $5^{\circ}$ da Lei Geral de Proteção de Dados estabelece:

Art. $5^{\circ}$ Para os fins desta Lei, considera-se:

11 SACOMANO, Jose Benedito; et. al. Indústria 4.0: conceitos e fundamentos. São Paulo: Blucher, 2018, p. 36-38.

12 BRASIL. Lei n 13.709, de 14 de agosto de 2018. Lei Geral de Proteção de Dados Pessoais. Brasília.

${ }^{13}$ DIAS, José de Aguiar. Da responsabilidade Civil. 6. ed. v.1, Rio de Janeiro: Forense, 1979, p. 1. 
I - dado pessoal: informação relacionada a pessoa natural identificada ou identificável;

II - dado pessoal sensível: dado pessoal sobre origem racial ou étnica, convicção religiosa, opinião política, filiação a sindicato ou a organização de caráter religioso, filosófico ou político, dado referente à saúde ou à vida sexual, dado genético ou biométrico, quando vinculado a uma pessoa natural;

III - dado anonimizado: dado relativo a titular que não possa ser identificado, considerando a utilização de meios técnicos razoáveis e disponíveis na ocasião de seu tratamento; ${ }^{14}$

Desta leitura, conclui-se que os dados são ligados a privacidade, intimidade e ao sigilo, residem no âmbito dos direitos fundamentais e da personalidade. Ademais, quando alguém possui essas informações sobre a pessoa é possível traçar sua personalidade utilizando da inteligência artificial.

Em recente documentário postado no YouTube pela BBC News Brasil no ano de 2018, na eleição norte americana de 2016, houve o estouro na mídia do caso Facebook e Cambridge Analytica S.A, que em síntese, a empresa Cambridge Analytica S.A conseguiu acesso aos dados de cerca de 87 milhões de usuários do facebook, podendo filtrar com base em um algoritmo a personalidade de cada estadunidense. A empresa coletava as informações pessoais dos usuários e seu histórico de curtida em páginas e publicações, e com esse arcabouço de informação, conseguia-se traçar o perfil eleitoral daquele cidadão.

Com esses dados em mãos, possibilitou-se, aos partidos que adquiriram essas informações, em tese, manipular as eleições, enviando anúncios direcionados as pessoas sobre as bandeiras defendidas por determinado candidato, e como já se sabia previamente a personalidade daquela pessoa, o anúncio direcionado era o que mais a agradava..$^{15}$

A inteligência artificial que é um dos elementos estruturantes da indústria 4.0 e seu uso traz riscos, relembrando, é um software que tem capacidade de resolver problemas e por consequência substituir humanos.

No que diz respeito a substituição do ser humano, não é algo distante, no âmbito do direito, pode-se dizer que a inteligência artificial é uma realidade, tribunais como o STJ, STF e TJMG já adotam alguns softwares que ajudam na eficiência dos julgados, vejamos conforme foi noticiado pelo TJMG: "[...] sessão inédita da $8^{\text {a }}$ Câmara Cível do Tribunal de Justiça de Minas Gerais julgou, com apenas um click no computador, um total de 280 processos. Em menos de um segundo, todos os processos foram julgados."16

De fato, pode ser um passo para o futuro com maior celeridade e eficiência nos julgados, todavia, em contrapartida terá uma menor sensibilidade dos julgadores na análise dos processos.

Muito embora a busca pela justiça numerária e automatizada seja tentadora, não se pode afastar a sensibilidade do judiciário. $\mathrm{O}$ tato e a figura do magistrado são importantes no processo constitucional.

\footnotetext{
14 BRASIL. Lei no 13.709, de 14 de agosto de 2018. Lei Geral de Proteção de Dados Pessoais. Brasília.

15 BBC News Brasil. Como a Cambridge Analytica analisou a personalidade de milhões de usuários no Facebook. 25 de Abril de 2018. 1 vídeo (4 min. 13s). Publicado por BBC News Brasil.

16 TJMG, TJMG utiliza inteligência artificial em julgamento virtual. Notícia. 2018
} 
Há profissões que são insubstituíveis, em virtude do subjetivismo que o ser humano tem, como bem lembra o filosofo Thoms Nagel:

\begin{abstract}
Até onde posso imaginar (e não consigo ir muito longe) isso me fornece dados apenas sobre o que poderia ser para mim comportar-me como um morcego se comporta. Mas esta não é a questão. Eu queria mesmo saber como é, para um morcego, ser um morcego. Mesmo se eu tentasse imaginar isso, estaria restrito às faculdades de minha própria mente, e estas são inadequadas para a tarefa. Eu não posso realizar a tarefa nem imaginando adições às minhas experiências atuais, nem graduais subtrações, nem imaginar eventuais combinações de adições, subtrações e modificações. ${ }^{17}$
\end{abstract}

A metáfora que Nagel induz é que adquirimos conhecimento, através da experiência, um software de inteligência artificial jamais será como um humano, pois afinal, trata-se de um software. Dessa forma, por mais que queiramos vivenciar as experiências de um morcego, jamais conseguiremos ser um ou sentir como um, pois não somos morcegos, estamos limitados a imaginação. Portanto, deve-se ter cautela ao delegar a um software, pois um processo judicial necessita do tato e sensibilidade do magistrado.

Não obstante, sobre o uso da inteligência artificial, tem-se o caso Vernon Prater e Brisha Borden, no qual buscava-se prever quem teria maior probabilidade de voltar reincidir criminalmente. Vernon possuía um largo antecedente criminal de roubos a mão armada, enquanto Brisha, que é negra, possuía algumas contravenções penais consumadas na adolescência, quando submetidos ao programa de inteligência artificial, foi apontada que Brisha era cinco vezes mais perigosa que Vernon, fato é, que foi um algoritmo preconceituoso. ${ }^{18}$

Outra situação gravíssima é em relação aos consumidores, que ao adentrarem em uma farmácia são seduzidos a descontos em troca de informar o CPF e outros dados pessoais, no ano de 2018 o Instituto de Referência em Internet e Sociedade submeteu ao Ministério Público de Minas Gerais uma representação, para que fosse investigado qual seria a real finalidade no armazenamento dos dados dos consumidores, a rede farmacêutica Drogaria Araújo S.A negou-se a informar e recusou ao termo de ajustamento da conduta, sendo multada pelo PROCON no montante de $\mathrm{R} \$ 7.930 .801,72 .{ }^{19}$

Duvida-se, que esta pratica, muito comum nas farmácias, tem finalidade diversa do desconto. Cogita-se que esses dados seriam vendidos as empresas de Planos de Saúde, pois, em tese, essas teriam acesso ao histórico de receituário daquele consumidor, sabendo qual a média anual que ele adoece, quais remédios consumiu e quais seus efeitos colaterais, podendo, com base em pesquisas saber qual o tempo estimado de vida daquela pessoa.

17 NAGEL, Thoms. Como é ser um morcego? (1974). Rev. abordagem gestalt. Trad: Josemar de Campo, Goiânia, v. 19, n. 1, p. 109-115, jul. 2013.

${ }^{18}$ ANGWIN, Julia; LARSON, Jeff; MATTU, Surya; KIRCHNER, Lauren. Machine Bias: There's software used across the country to predict future criminals. And it's biased against blacks. May 23, 2016.

19 MPMG. Drogaria Araújo deverá pagar multa de R\$ 7 milhões por capturar CPF dos consumidores. Belo Horizonte, 2018 
Pelo exposto, com o advento da Lei Geral de Proteção de Dados, espera-se que haja a efetiva proteção ao titular dos dados, bem como a devida reparação civil pelos danos causados em decorrência do tratamento indevido dessas informações.

\section{DIREITOS DA PERSONALIDADE}

A Constituição da República de 1988 , no seu artigo $1^{\circ}$, inciso III, colocou o ser humano como centro de suas atenções, estabelecendo como direito fundamental a sua dignidade. Nesta esteira, pode-se dizer que a dignidade da pessoa deve permanecer intacta, sem violações, há então uma obrigação de não fazer das pessoas com elas mesmas, isto é, não se pode violar a dignidade do seu semelhante.

Historicamente como bem lembra José Joaquim Gomes Canotilho "[...] o processo de fundamentalização, constitucionalização e positivação dos direitos fundamentais colocou o indivíduo, a pessoa, o homem, como centro da titularidade de direitos" ${ }^{20}$

Além disto, é incontroverso que foi no pós-segunda guerra que enalteceu-se o ser humano, os Estados abdicaram de parte da sua soberania em prol da paz mundial, do meio ambiente, da globalização e da dignidade humana.

Ressalta-se que os direitos humanos estão no plano internacional, enquanto os direitos fundamentais no plano da constitucionalização de cada Estado, e os diretos da personalidade repousam na esfera privada, como ensina Orlando Gomes: "os direitos de personalidade são direitos subjetivos privados." 21

Em relação aos direitos da personalidade, eles possuem um rol exemplificativo, uma vez que não se consegue dizer ao certo, o que é essencial a cada pessoa ou então aquilo que necessariamente precisa de proteção, a jurista Eliane Buarque leciona que: "A proteção aos bens não patrimoniais é uma questão que acompanha o processo civilizatório e, quanto mais desenvolvido for o processo civilizatório, maior é a consciência social." ${ }^{22}$ Assim, com o tempo, a própria sociedade vai dando proteção àquilo que precisa, o que justifica ser um rol exemplificativo.

Nesse mesmo sentido obtempera o jurista Silvio de Salvo Venosa, que de forma conclusiva sobre a não exaustividade dos direitos da personalidade preleciona:

A personalidade jurídica, juntamente com a noção de dignidade, possui valor jurídico insuscetível de ser totalmente tipificado. Sua proteção é ampla, impossível de ser descrita em situações normativas. A tutela jurídica será aplicada nos casos concretos específicos. ${ }^{23}$

${ }^{20}$ CANOTILHO, José Joaquim Gomes. Direito constitucional e teoria da constituição. 7. ed. Coimbra: Edição Almedina, 2003, p. 416

${ }^{21}$ GOMES, Orlando. Direitos de personalidade. Revista de informação legislativa, v. 3. n. 11. p. 39-48, set. 1966, p. 43.

22 BUARQUE, Eliane. O dano existencial como uma nova modalidade de dano não patrimonial: a necessidade da ampliação do princípio da função social da responsabilidade civil e a busca da reparação integral do dano à pessoa. Revista IBERC. v.2. n.2. p, 01-22. mai./ago. 2019, p. 12.

${ }^{23}$ VENOSA, Silvio de Salvo. A Constituição de 1988 e o Direito Civil. In: MORAES, Guilherme Peña de; (Org.). 30 anos da Constituição Federal e o direito brasileiro. Rio de Janeiro: Forense, 2018, p. 477. 
Portanto, a norma jurídica sempre estará sofrendo releituras, pois os bens jurídicos importantes para determinada sociedade mudam conforme a nova realidade, é um efeito do processo civilizatório. Assim, ensina o Ministro Paulo de Tarso Sansevrino "[...] o caminho entre a necessidade humana e o direito subjetivo, se o legislador ainda não o percorreu, e há um interesse legítimo, deve o Juiz percorrê-lo, ou senão, ficará seu titular desamparado." ${ }^{24} \mathrm{E}$ na sociedade da informação ou do conhecimento, o maior bem jurídico a ser tutelado é o da privacidade.

\title{
3.1. Privacidade: direito a intimidade e ao sigilo
}

O direito à privacidade é um direito fundamental tipificado na Constituição da República e também um direito da personalidade conforme hermenêutica civilista, é classificado no âmbito privado, como um direito que está no rol dos direitos psíquicos, vejamos conforme a proposta de Carlos Alberto Bittar:

\begin{abstract}
Por isso, podemos distribuir os direitos da personalidade em: a) direitos físicos; b) direitos psíquicos; c) direitos morais. Os primeiros são referentes a componentes materiais da estrutura humana (a integridade corporal, compreendendo: o corpo, como um todo; os órgãos; os membros; a imagem, ou efígie); os segundos, relativos a elementos intrínsecos à personalidade (integridade psíquica, compreendendo: a liberdade; a intimidade; o sigilo); e os últimos, respeitantes a atributos valorativos (ou virtudes) da pessoa na sociedade (o patrimônio moral, compreendendo: a identidade; a honra; as manifestações do intelecto). ${ }^{25}$
\end{abstract}

Sabendo que o direito à privacidade é um direito da personalidade, conclui-se que compõe aquilo que é essencial a pessoa, e que qualquer violação afetará sua dignidade, pois afeta sua vida privada. Ademais, ensina Gilberto Jabur que: "O direito à vida privada posiciona-se como gênero ao qual pertencem o direito a intimidade e o direito ao segredo." 26

Nesta linha de raciocínio, qualquer violação a esses direitos acarretará para o lesado a pretensão a reparação, seja a pessoa natural ou a pessoa jurídica, conquanto, a Lei Geral de Proteção de Dados, serve, a princípio, tão somente a pessoa humana conforme disposto no seu artigo $1^{\circ}$, e este diploma legal é norteado por alguns fundamentos, elencados no artigo $2^{\circ}$ vejamos: Art. $2^{\circ} \mathrm{A}$ disciplina da proteção de dados pessoais tem como fundamentos: I - o respeito à privacidade; [...] IV - a inviolabilidade da intimidade, da honra e da imagem;

Da leitura do dispositivo que regula os fundamentos da LGPD não é possível observar a tutela específica dos dados, isto porque, o sigilo aos dados está no interior do direito a intimidade, e que está no interior da privacidade, senão vejamos: "No campo do direito à intimidade são

${ }^{24}$ SANSEVERINO, Paulo de Tarso Vieira. Princípio da Reparação integral: indenização no Código Civil. São Paulo: Saraiva, 2011, p. 20.

${ }^{25}$ BITTAR, Carlos Alberto. Os direitos da personalidade. 8. ed. rev. aum. e mod. por Eduardo C. B. Bittar. São Paulo: Saraiva, 2015, p. 49.

${ }^{26}$ JABUR, Gilberto Haddad. Liberdade de pensamento e direito à vida privada: conflitos entre direitos da personalidade. São Paulo: Revista dos Tribunais, 2000, p. 256. 
protegidos, dentre outros, os seguintes bens: confidências; informes de ordem pessoal (dados pessoais) [...]."27

Mesma conclusão que o Superior Tribunal Federal chegou ao julgar a medida cautelar proposta na ADI 6.387, que está pendente a publicação o Acordão, nas linhas que se seguem a fundamentação ipisi litteris da eminente relatora Ministra Rosa Weber:

Tais informações, relacionadas à identificação - efetiva ou potencial - de pessoa natural, configuram dados pessoais e integram, nessa medida, o âmbito de proteção das cláusulas constitucionais assecuratórias da liberdade individual (art. $5^{\circ}$, caput), da privacidade e do livre desenvolvimento da personalidade (art. $5^{\circ}, \mathrm{X}$ e XII). Sua manipulação e tratamento, desse modo, hão de observar, sob pena de lesão a esses direitos, os limites delineados pela proteção constitucional.

(ADI 6387 MC-Ref, Relator(a): ROSA WEBER, Tribunal Pleno, julgado em 07/05/2020, PROCESSO ELETRÔNICO DJe-270, DIVULG 11-11-2020 PUBLIC 12-11-2020)

Pelo exposto, a Constituição da República de 1988 em seu artigo $5^{\circ}$, inciso XII assegura de forma clara a privacidade e como corolário a proteção de dados.

Ademais, é importante ressaltar que é compreensível o que seria direito a privacidade, direito a intimidade e direito ao sigilo, mas a conceituação nem sempre é fácil, isto ocorre, porque cada pessoa tem para si aquilo só a pertence e a mais ninguém.

Neste árduo trabalho de conceituar, os juristas Nelson Rosenvald e Cristiano Farias entendem que a privacidade:

[...] é o refúgio impenetrável pela coletividade, merecendo proteção. Ou seja, é o direito de viver a sua própria vida em isolamento, não sendo submetido à publicidade que não provocou, nem desejou. Consiste no direito de obstar que a atividade de terceiro venha a conhecer, descobrir ou divulgar as particularidades de uma pessoa. ${ }^{28}$

Por sua vez, o direito a intimidade na perspectiva de Rui Stoco: "Será aquilo que não se quer compartilhar com ninguém mais, o direito de estar consigo mesmo."29

$\mathrm{E}$ os dados encontram-se protegidos no direito à intimidade, que está abarcado pelo direito fundamental da privacidade, em contrapartida, o direito ao sigilo ou o direito ao segredo é um direito que nasce para o titular dos dados no momento em que ele abdica parcialmente do seu direito à privacidade, ou seja, quando são compartilhados com operadores, controladores ou provedores. Pode-se dizer, que o direito ao sigilo possui os mesmos efeitos de uma obrigação propter rem, isto é, quem possui os dados é obrigado a mantê-lo em sigilo, sob pena de violar o direito do titular e proprietário dos dados.

${ }^{27}$ BITTAR, Carlos Alberto. Os direitos da personalidade. 8. ed. rev. aum. e mod. por Eduardo C. B. Bittar. São Paulo: Saraiva, 2015, p. 173.

${ }^{28}$ ROSENVALD, Nelson; FARIAS, Cristiano Chaves de. Curso de Direito Civil: parte geral e LINDB. 15. Ed. rev., ampl. e atual. Salvador: JusPodivm, 2017, p. 268.

29 STOCO, Rui. Tratado de Responsabilidade Civil: doutrina e jurisprudência. 10. ed. rev. atual. e reform. São Paulo: Revista dos Tribunais, 2014, p. 2167. 
Ademais, os responsáveis que possuem o dever ético e legal de não violarem o direito ao sigilo do titular dos dados, são denominados pela LGPD de controladores e operadores, senão vejamos:

Art. $5^{\circ}$ Para os fins desta Lei, considera-se:

$\mathrm{VI}$ - controlador: pessoa natural ou jurídica, de direito público ou privado, a quem competem as decisões referentes ao tratamento de dados pessoais;

VII - operador: pessoa natural ou jurídica, de direito público ou privado, que realiza o tratamento de dados pessoais em nome do controlador; ${ }^{30}$

Não raro, na sociedade da informação a todo momento é compartilhado com os operadores e controladores informes pessoais para ter acesso a determinados sites ou então aplicativos, cria-se um nome, um login, um e-mail, uma senha, às vezes compartilha-se a localização, e todas essas informações são dados pessoais ou sensíveis do titular, que merecem a devida proteção com fim de resguardar a privacidade e intimidade do usuário.

Com fulcro no princípio da boa-fé objetiva do direito privado a LGPD em seu artigo $6^{\circ}$ elenca alguns princípios, sendo eles: finalidade, adequação, necessidade, livre acesso, qualidade dos dados, tratamento transparente, segurança, prevenção, não discriminação, responsabilização e prestação de contas.

Frisa-se, que nos ensinamentos de Manuel Atieza as diversas definições de norma jurídica, no atual sistema, mostram-se mais acertado compreendê-la como gênero do qual são espécies as regras e os princípios. ${ }^{31}$

Pelo exposto, havendo a violação de qualquer desses princípios ou então de qualquer outra conduta tipificada nesta lei, que viole a privacidade e intimidade do titular dos dados, configurará a ilicitude ou então o ato ilícito por equiparação, que são requisitos da responsabilidade civil.

Nota-se que se utiliza da locução ilicitude, por se trata de responsabilidade objetiva, conforme será abordado no próximo tópico, nesse mesmo sentido, leciona Sergio Cavalieri Filho: "Não há que se falar em ato lícito se em todos os casos de responsabilidade objetiva há sempre a violação de um dever jurídico preexistente, o que configura a ilicitude."32

\section{CONSIDERAÇÕES SOBRE A RESPONSABILIDADE CIVIL}

Responsabilidade está intrinsicamente ligado ao dever de diligência, cautela e cuidado, e no âmbito jurídico pode-se dizer que é uma obrigação decorrente de uma violação, que poderá ser contratual ou extracontratual, por isso a responsabilidade civil é considerada também uma fonte do direito obrigacional.

\footnotetext{
${ }^{30}$ BRASIL. Lei n 13.709, de 14 de agosto de 2018. Lei Geral de Proteção de Dados Pessoais. Brasília.

31 ATIENZA, Manuel. As razões do direito: teorias da argumentação jurídica. Trad: Maria Cristina Guimarães Cupertino. 2. ed. Rio de Janeiro: Forense, 2014, p. 213.

32 CAVALIERI FILHO, Sérgio. Programa de responsabilidade civil. 13. ed. Rio de Janeiro: Atlas, 2018, p. 20.
} 
Entrelinhas, pode-se dizer que a responsabilidade civil é somente um substrato da responsabilidade jurídica, conceituada por Álvaro Villaça Azevedo como: "A responsabilidade civil nada mais é que o dever de indenizar o dano." 33

Nesta toada, vai além disto, pois é a consequência da vida em sociedade, a responsabilidade é a dimensão de justiça existente no grupo social, que traduz na sua essência o não causar danos e sempre buscar repará-los quando causados.

Assim ensina Sergio Cavalieri Filho: "Há, assim, um dever jurídico originário, chamado por alguns de primário, cuja violação gera um dever jurídico sucessivo, também chamado de secundário, que é o de indenizar o prejuízo." 34

E como todo instituo do direito privado a responsabilidade civil necessita de funções, que é aquilo que motiva sua existência, de forma inteligente e precisa os juristas Nelson Rosenvald, Cristiano Chaves e Felipe Braga Netto ilustram:

\begin{abstract}
Cremos que no direito brasileiro do alvorecer do século XXI a conjunção destas orientações permite o estabelecimento de três funções para a responsabilidade civil: (1) função reparatório: a clássica função de transferência dos danos do patrimônio do lesante ao lesado como forma de reequilíbrio patrimonial; (2) função punitiva: sanção consistente na aplicação de uma pena civil ao ofensor como forma de desestimulo de comportamentos reprováveis; (3) função precaucional: possui o objetivo de inibir atividades potencialmente danosas. ${ }^{35}$
\end{abstract}

O instituto da responsabilidade civil é de suma importância visando sempre a mantença da ordem, com respaldo em dois deveres, "[...] um dever jurídico preexistente, de não lesar outrem, surgindo um outro posterior que é o de indenizar e recompor o equilíbrio social." ${ }^{36}$

Não é necessário discorrer sobre o aspecto histórico do instituto, nem mesmo criar conceitos novos, já que se alcançou a excelência. O que não quer dizer que está por finalizada a possibilidade de novos avanços, por isso, deve-se atentar aos novos danos que decorre da violação do direito da privacidade, intimidade e sigilo, mediante inobservâncias no tratamento de dados.

Com efeito, o jurista Caio Mario da Silva Pereira ensina o motivo pelo qual, deve-se buscar progredir com o instituto da reparação civil: "A proteção à pessoa humana desempenha papel central." 37

\title{
4.1. Responsabilidade civil contratual e extracontratual: tratamento dos dados
}

A responsabilidade civil poderá ser contratual ou extracontratual, no que diz respeito a primeira, é importante aferir uma relação jurídica preliminar entre as partes, em que haverá a

${ }^{33}$ AZEVEDO, Álvaro Villaça. Teoria Geral das Obrigações. Responsabilidade Civil. 10. ed. São Paulo: Atlas, 2004, p. 276.

${ }^{34}$ CAVALIERI FILHO, Sérgio. Programa de responsabilidade civil. 13. ed. Rio de Janeiro: Atlas, 2018, p. 13. ${ }^{35}$ ROSENVALD, Nelson; FARIAS, Cristiano Chaves de; BRAGA NETTO, Felipe Peixoto. Responsabilidade Civil. 4. ed. rev. atual. Salvador: Juspodivm, 2017c, p. 62.

${ }^{36} \mathrm{CHADI}$, Ricardo. Indenização por perda de uma chance e sua adequada fundamentação. In: GUERRA, Ricardo; DINIZ, Giovanni Antonio, CHADI, Ricardo (Org). Direito do Trabalho. 1. ed. Carderno 2. Belo Horizonte: Fumarc: 2015, p. 425.

${ }^{37}$ PEREIRA, Caio Mário da Silva. Responsabilidade Civil. Atual. Gustavo Tepedino. 12. ed. rev., atual. e ampl Rio de Janeiro: Forense, 2018, p. 15. 
necessidade dosar a culpa no inadimplemento contratual, sendo parcial incorrerá a multa remuneratória, sendo total a multa compensatória, sem prejuízo de indenização suplementar quando previsto no instrumento contratual. Em relação a segunda, independe de relação jurídica preliminar entre as partes, e o inadimplemento dar-se-á quando o ofensor viola um dever jurídico de não lesar o outrem.

Impende salientar que há ainda uma terceira vertente do inadimplemento contratual, denominada de violação positiva do contrato, que é em suma, quando não há a observância dos deveres anexos da boa-fé objetiva em uma relação contratual, muito embora, haja o cumprimento das cláusulas contratuais, a conduta tomada por uma parte perante a outra ofende a boa-fé objetiva, cita-se a omissão de informação quanto ao objeto do negócio jurídico, que independe da culpa, conforme estabelecido no enunciado 24 do Conselho Justiça Federal.

Pode-se dizer que a conduta que causa a violação positiva do contrato advém de um abuso de direito estancada no artigo 187 do Código Civil, pois conforme a redação legal: "Também comete ato ilícito o titular de um direito que, ao exercê-lo, excede manifestamente os limites impostos pelo seu fim econômico ou social, pela boa-fé ou pelos bons costumes."

Nesse sentido, a boa-fé objetiva é um dever que não advém do contrato, mas por princípios norteadores de todo o direito privado, portanto, se uma pessoa tem o dever ético de cumprir com os deveres anexos, e toma uma conduta positiva ou omissiva a fim de não observálos estará abusando do seu direito.

Dito isso, em relação ao tratamento de dados é possível a configuração da responsabilidade civil de forma contratual, cita-se por exemplo, quando o controlador contrata um operador para tratar dos dados, e este último não observa as cláusulas contratuais. É possível falar em inadimplemento positivo do contrato no tratamento de dados, por exemplo, quando um consumidor realiza um contrato de compra e venda e informa seus dados a empresa em troca de desconto, mas esta última não informa a finalidade do armazenamento dos dados.

Além disto é mais que incontroverso a configuração da responsabilidade civil extracontratual, inclusive, na maioria das vezes, cita-se os vazamentos de dados, cujo o Egrégio TJMG decidiu recentemente:

EMENTA: APELAÇÃO CÍVEL - AÇÃO DE INDENIZAÇÃO - VIOLAÇÃO DE SIGILO DE DADOS POR ATAQUE CIBERNÉTICO - DANO MORAL CONFIGURADO - REDUZIR VALOR DA INDENIZAÇÃO. - As consequências que decorreram da invasão dos dados cadastrais da autora por terceiros desautorizados, causaram abalos moral, passíveis de reparação. - Em acordo com as peculiaridades do caso, entendo que o valor da indenização fixada pelo juiz sentenciante deve ser reduzido, $\mathrm{O}$ que proporciona a reparação pecuniária do dano à ofendida e o efeito pedagógico ao ofensor, evitando-se a reiteração de condutas dessa natureza, sem que haja enriquecimento ilícito sem causa. (TJMG - Apelação Cível 1.0000.19.061299-4/001, Relator(a): Des.(a) Shirley Fenzi Bertão, $11^{a}$ CÂMARA CÍVEL, julgamento em 14/08/2019, publicação da súmula em 19/08/2019)

Curiosamente, os dados são bens incorpóreos, e o mero tratamento, não configura contrato de depósito, já que neste contrato o objeto deve ser móvel e material. Portanto, por mais que o titular dos dados utilize de um serviço ou produto virtual que exija seus dados, não haverá 
nenhuma configuração contratual, mas mero efeitos da detenção deles por parte dos operadores e controladores, que se obrigam a protege-los. E como se sabe a detenção é uma posse que precede uma subordinação aos proprietários dos dados, contudo, não é cabível nenhuma ação possessória, já que há a incompatibilidade da apreensão material em bens imateriais, nesse sentido é o que dita a súmula 228 do STJ.

\subsection{Responsabilidade objetiva ou subjetiva}

A responsabilidade civil possui pressupostos para sua configuração, conforme a teoria tetrapartida são eles: a) ato ilícito, b) culpa, c) nexo causal e d) dano, quando há a necessidade dos quatro pressupostos, estaremos diante da responsabilidade civil subjetiva elencada no artigo 186 do Código Civil, por outro lado, a responsabilidade civil objetiva está elencada no artigo 927 do Código Civil, e que "[...] sobejam banidos da obrigação de indenizar os pressupostos do ato ilícito e da culpa, concentrando-se a atenção do civilista nos pressupostos do risco da atividade, nexo causal e dano." 38

Quando se trata da responsabilidade civil da lei geral de proteção de dados, há uma controvérsia enorme, se será responsabilidade subjetiva ou objetiva, sendo que na verdade, podese afirmar com toda certeza que é objetiva. Para tanto, é preciso estudar o ponto nevrálgico da controvérsia, a culpa!

Buscando um conceito de culpa na perspectiva clássica da doutrina civilista Roberto Ruggiero preleciona:

Qualquer comportamento injusto, quer seja um fato positivo (comissão), quer negativo (omissão), quer um fato praticado com o deliberado propósito de prejudicar outrem ou de violar a esfera jurídica alheia, quer um fato praticado sem tal propósito e consistente numa diligência. ${ }^{39}$

Se ainda subsistisse a culpa presumida, certamente na proteção dos dados teríamos a culpa in custodiando, todavia, o CC/02 baniu as presunções de culpa, mas esta foi uma ponte para se alcançar a teoria objetiva, e esta por sua vez, não quer presumir a culpa, mas invertê-la, pois, conforme se sabe "a prova da culpa, em muitos casos, é verdadeiramente diabólica, erigindo-se em barreira intransponível para o lesado." 40

Na teoria objetiva não existe o afastamento da prova da culpa, na verdade, o que ocorre é uma inversão probatória, cujo ônus é de quem causou o dano, devendo provar que não agiu com culpa. Logicamente, se não provada, a culpa será presumida, bastando que haja prova do fato que levou ao evento danoso. E este fato poderá ter origem na vedação de um dispositivo legal ou então uma atividade que gera risco, conforme as teorias do risco.

${ }^{38}$ ROSENVALD, Nelson; FARIAS, Cristiano Chaves de; BRAGA NETTO, Felipe Peixoto. Responsabilidade Civil. 4. ed. rev. atual. Salvador: Juspodivm, 2017c, p. 152.

${ }^{39}$ RUGGIERO, Roberto. Instituições de direito civil. Trad. de Ary dos Santos, Antônio Chaves e Fábio Maria de Mattia. 3. ed. v.3. São Paulo: Saraiva, 1973, p. 388.

${ }^{40}$ CAVALIERI FILHO, Sérgio. Programa de responsabilidade civil. 13. ed. Rio de Janeiro: Atlas, 2018, p. 57. 
O risco pode ser conceituado: "é probabilidade de dano, importando, isso, dizer que aquele que exercer uma atividade perigosa deve-lhe assumir os riscos e reparar o dano dela decorrente." 41

Além do mais, existe as espécies da teoria do risco, sendo elas: teoria do risco criado, teoria do risco administrativo, teoria do risco proveito, teoria do risco profissional e teoria do risco integral.

No que diz respeito a LGPD, terá relevância a teoria do risco proveito e do risco criado, porque a partir delas pode-se analisar a responsabilidade civil dos tratadores de dados. Da leitura do artigo $5^{\circ}, \mathrm{X}$ da LGPD, que refere ao tratamento de dados, trata-se de uma norma jurídica plurinuclear e nada obsta que determina pessoa colete e utilize os dados e com eles ganhe proveito, imagine, o Facebook S.A que coleta e armazena os dados e com eles retira proveito direcionado anúncios publicitários aos usuários.

Frisa-se que haverá responsabilidade pelo risco proveito, quando do tratamento de dados tira-se proveito, com efeito, quem deverá provar que não retira proveitos é o próprio causador do dano, conforme a teoria objetiva, onde há bônus haverá ônus. Contudo, se a pessoa não retira proveito dos dados, poderá ser imputada pela teoria do risco criado, que nos ensinamentos de Eugênio Facchini Neto:

Dentro da teoria do risco criado, destarte, a responsabilidade não é mais a contrapartida do proveito ou lucro particular, mas sim a consequência inafastável da atividade em geral. [...] a qualquer ato do homem que seja potencialmente danoso a esfera jurídica de seus semelhantes. ${ }^{42}$

Embora a pessoa física ou jurídica, não tenha como objetivo finalístico o tratamento dos dados, mas pratica qualquer das condutas do artigo $5, X$ da LGPD para desenvolver sua atividade principal, estará criando um risco ao titular dos dados.

Não raro, é comum sociedades empresárias armazenarem dados do consumidor mesmo exercendo outra atividade empresarial, assim, em razão da atividade exercida, que não necessariamente precisa ser voltada a área da tecnologia, consuma qualquer das condutas referente ao tratamento de dados, estará criando um risco ao titular dos dados.

Portanto, tratar da privacidade, intimidade e sigilo alheio em ambiente virtual, certamente gera riscos. Não obstante, obtempera os juristas Renato Blum e Marcos Gomes: "[...] para determinadas atividades nas quais se devem assumir riscos implícitos a ela, o que pode se aplicar à quase totalidade das relações jurídicas que envolvem o meio virtual, haverá responsabilidade independentemente de culpa." 43

Nesse sentido é o que estabelece o artigo 42 da LGPD:

41 CAVALIERI FILHO, Sérgio. Programa de responsabilidade civil. 13. ed. Rio de Janeiro: Atlas, 2018, p. 225. 42 NETO, Eugenio Facchini. Da responsabilidade civil no novo Código. Revista Jurídica, Porto Alegre: Notadez. Ano 55, junho, n 356, 2007, p. 38.

43 BLUM, Renato Opice; BRUNO, Marcos Gomes. O novo Código Civil e o direito eletrônico. In: DELGADO, Mário Luiz; ALVES, Jones Figueirêdo (Org.). Questões controvertidas no novo Código Civil. São Paulo: Método, 2003, p. 213. 
Art. 42. O controlador ou o operador que, em razão do exercício de atividade de tratamento de dados pessoais, causar a outrem dano patrimonial, moral, individual ou coletivo, em violação à legislação de proteção de dados pessoais, é obrigado a repará-lo. ${ }^{44}$

O diploma legal imputa ao controlador ou ao operador, que em razão de atividade de tratamento, e não em razão da atividade empresária (principal) exercida, portanto, uma não se confunde com a outra.

Na parte final da redação, a lei diz, em violação à legislação, e como dito, será violação tanto a norma jurídica quanto a princípios, e a LGPD é norteada por uma série de princípios e muitos deles estão abarcados pelos deveres anexos da boa-fé objetiva e já se sabe que havendo violação da boa-fé objetiva, haverá uma responsabilização objetiva, nos termos do enunciado 24 do Conselho da Justiça Federal.

Com efeito, quando se fala em risco a palavra antônimo é segurança, e de forma incisiva a LGPD estabelece no artigo 44, parágrafo único a seguinte redação: "Art. 44 [...] Parágrafo único. Responde pelos danos decorrentes da violação da segurança dos dados o controlador ou o operador que, ao deixar de adotar as medidas de segurança previstas no art. 46 desta Lei, der causa ao dano." (BRASIL, 2018). Dessa forma, também haverá violação, quando o tratador dos dados não adota medidas de segurança para manutenção do sigilo da privacidade alheia.

Curiosamente sabendo que foram as revoluções industriais que levou a adoção da teoria objetiva, não há motivos para regredir a teoria subjetiva na quarta revolução industrial.

\subsection{Dano moral in re ipsa}

A responsabilidade civil pressupõe um dano, por isso "falar em dano significa dar-lhe um sentido sempre ligado a ideia de prejuízo ou perda." 45

Preliminarmente, é preciso considerar qual o bem jurídico tutelado pela Lei Geral de Proteção de Dados e indubitavelmente são os direitos da personalidade, sobretudo a privacidade e intimidade do sujeito de direito.

Pelo exposto, sabendo que o tratamento de dados poderá lesar direitos da personalidade, surge o dano moral que é compreendido como uma espécie de danos extrapatrimoniais, conceituado como:

Dano moral não mais se restringe à dor, tristeza e sofrimento, estendendo a sua tutela a todos os bens personalíssimos - os complexos de ordem ética -, razão pela qual podemos defini-lo, de forma abrangente, como sendo uma agressão a um bem ou atributo da personalidade. ${ }^{46}$

44 BRASIL. Lei no 13.709, de 14 de agosto de 2018. Lei Geral de Proteção de Dados Pessoais. Brasília.

45 STOCO, Rui. Tratado de Responsabilidade Civil: doutrina e jurisprudência. 10. ed. rev. atual. e reform. São Paulo: Revista dos Tribunais, 2014, p. 1661.

${ }^{46}$ CAVALIERI FILHO, Sérgio. Programa de responsabilidade civil. 13. ed. Rio de Janeiro: Atlas, 2018, p. 118. 
Por muito tempo assimilou-se o dano moral ao aborrecimento, estresse, dor, mal sentimento, contudo, isso são sentimentos, ou seja, são os efeitos de um dano. O dano já foi causado, e ele poderá ou não gerar sentimentos, não se pode estudar os institutos pelos seus efeitos, os tribunais não podem julgar com base no sentimento do lesado, por isso o dano moral deve ser entendido como violação aos direitos da personalidade, que eventualmente, poderá, mas não necessariamente, ter como efeito danos aos sentimentos. O bem jurídico a ser reparado são os direitos da personalidade e não o que a pessoa sentiu.

Nesse mesmo sentido, obtempera Nelson Rosenvald, Cristiano Chaves e Felipe Braga:

Ocorre que o dano moral nada tem a ver com a dor, mágoa ou sofrimento da vítima ou de seus familiares: O pesar e consternação daqueles que sofrem um dano extrapatrimonial não passam de sensações subjetivas, ou seja, sentimentos e vivências eminentemente pessoais e intransferíveis, pois cada ser humano recebe os golpes da vida de forma única, conforme o seu temperamento e condicionamentos. Afinal, "cada um sabe a dor e a delícia de ser o que é. ${ }^{47}$

Em relação ao dano moral in re ipsa, tende-se a sedimentar que qualquer dano a direitos fundamentais ou da personalidade será presumido pelos próprios fatos.

De modo mais amplo, os direitos da personalidade oferecem um conjunto de situações definidas pelo sistema jurídico, inerentes à pessoa, cuja lesão faz incidir diretamente a pretensão aos danos morais, de modo objetivo e controlável, não sendo necessária a prova do prejuízo ou recurso à existência de dor moral ou psíquica, sofrimentos ou incômodos, nesta linha de ideias coaduna o jurista Paulo Lobo, in verbis:

A responsabilidade opera-se pelo simples fato da violação (damnu in re ipsa); assim, verificada lesão a direitos da personalidade, surge a necessidade de reparação do dano moral. ${ }^{48}$

Sabendo então que a privacidade é um direito inerente a pessoa humana e por isso é considerado como um direito fundamental e da personalidade, qualquer violação ao tratamento de dados violará a privacidade de outrem, nascendo, então, o dano moral in re ipsa.

Recentemente o Superior Tribunal de Justiça em seu informativo jurisprudencial 660 que julgou o Resp. 1.758.799/MG, destacou que:

CONFIGURA DANO MORAL IN RE IPSA a ausência de comunicação acerca da disponibilização/comercialização de informações pessoais em bancos de dados do consumidor." (REsp 1.758.799-MG, Rel. Min. Nancy Andrighi, Terceira Turma, por unanimidade, julgado em 12/11/2019, DJe 19/11/2019)

Dessa forma, por mais que o julgado ventile sobre a comercialização ou disponibilização de dados, seu objeto é resguardar a privacidade do sujeito de direito, portanto, o tratamento indevido dos dados, ou a não observância da mantença de medidas de segurança com fito de

${ }^{47}$ ROSENVALD, Nelson; FARIAS, Cristiano Chaves de; BRAGA NETTO, Felipe Peixoto. Responsabilidade Civil. 4. ed. rev. atual. Salvador: Juspodivm, 2017c, p. 297.

48 LÔBO, Paulo. Direito Civil: obrigações. 7. ed. v.2. São Paulo: Saraiva Educação, 2019, p. 49. 
resguardar o sigilo dos dados, lesiona direitos da personalidade, e terá por consequência um dano moral presumido.

\section{CONSIDERAÇÕES FINAIS}

Por tudo que foi exposto, pode-se concluir que na sociedade da informação e virtualizada, há uma premente necessidade de promover a proteção da privacidade dos usuários, isto porque, a todo instante, as pessoas compartilham informações e dados pessoais em sites e aplicativos, além dos desenvolvedores de produtos e serviços inteligentes utilizam-se de uma base de dados para desenvolve-los.

Dessa forma, sabendo que os dados são intrínsecos ao direito da intimidade que é abarcado pelo direito fundamental da privacidade, faz nascer para o possuidor dos dados, que são os operadores e controladores, o direito de manter em sigilo essas informações pertencentes ao titular dos dados, bem como tomar boas medidas afim de resguardá-los de terceiros invasores.

Conforme sustentado, o tratamento de dados consiste em uma norma jurídica plurinuclear, e certamente, tratar da privacidade alheia é um risco, ainda mais em ambiente virtual, motivo pelo qual, fala-se em responsabilidade objetiva. Nada impede, que seja adotada a teoria do risco proveito, quando os tratadores de dados retiram proveito dos dados, ou então seja adotada a teoria do risco criado, mesmo que a pessoa física ou jurídica, não tenha como objetivo finalístico o tratamento dos dados, mas pratica qualquer das condutas do artigo 5, X da LGPD para desenvolver sua atividade principal, estará criando um risco ao titular dos dados.

No que diz respeito aos danos causados ao titular dos dados, este será in re ipsa, uma vez que o bem jurídico tutelado pela LGPD é um direito da personalidade.

\section{REFERÊNCIAS}

ALMEIDA, Paulo Samuel de. Indústria 4.0: princípios básicos, aplicabilidade e implantação na área industrial. São Paulo: Érica, 2019.

ANGWIN, Julia. LARSON, Jeff. MATTU, Surya. KIRCHNER, Lauren. Machine Bias. Disponível em: https://www.propublica.org/article/machine-bias-risk-assessments-in-criminal-sentencing. Acesso em 28 de ago. de 2020.

ATIENZA, Manuel. As razões do direito: teorias da argumentação jurídica. Trad: Maria Cristina Guimarães Cupertino. 2. ed. Rio de Janeiro: Forense, 2014.

AZEVEDO, Álvaro Villaça. Teoria Geral das Obrigações. Responsabilidade Civil. 10. ed. São Paulo: Atlas, 2004.

BAUMAN, Zygmunt. 44 cartas do mundo líquido moderno. Rio de Janeiro: Zahar, 2011.

BBC News Brasil. Como a Cambridge Analytica analisou a personalidade de milhões de usuários no Facebook. 25 de Abril de 2018. 1 vídeo (4 min. 13s). Publicado por BBC News Brasil. Disponível em: https://www.youtube.com/watch?v=x1SnHHby0wA. Acesso em 28 de ago. de 2020. 
BITTAR, Carlos Alberto. Os direitos da personalidade. 8. ed. rev. aum. e mod. por Eduardo C. B. Bittar. São Paulo: Saraiva, 2015.

BITTAR, Eduardo C. B. Curso de filosofia do direito. 14. ed. Rio de Janeiro: Atlas, 2019.

BLUM, Renato Opice; BRUNO, Marcos Gomes. O novo Código Civil e o direito eletrônico. In: DELGADO, Mário Luiz; ALVES, Jones Figueirêdo (Org.). Questões controvertidas no novo Código Civil. São Paulo: Método, 2003.

BUARQUE, Eliane. O dano existencial como uma nova modalidade de dano não patrimonial: a necessidade da ampliação do princípio da função social da responsabilidade civil e a busca da reparação integral do dano à pessoa. Revista Iberc. v.2. n.2. mai./ago. 2019. p, 01-22. Disponível em: http://revistaiberc.responsabilidadecivil.org/iberc/issue/view/5. Acesso em: 02 de dez. de 2019

BRASIL. Constituição da República Federativa do Brasil de 1988. Brasília, DF: Presidência da República, [2016]. Disponível em: http://www.planalto.gov.br/ccivil_03/Constituicao/ Constituiçao.htm. Acesso em: 29 ago. 2020.

BRASIL. Lei n 13.709 , de 14 de agosto de 2018. Lei Geral de Proteção de Dados Pessoais. Brasília. Disponível em: http://www.planalto.gov.br/ccivil_03/_ato2015-2018/2018/lei/L13709.htm. Acesso em: 29 ago. 2020.

CANOTILHO, José Joaquim Gomes. Direito constitucional e teoria da constituição. 7.ed. Coimbra: Edição Almedina, 2003.

CAVALIERI FILHO, Sérgio. Programa de responsabilidade civil. 13. ed. Rio de Janeiro: Atlas, 2018.

CHADI, Ricardo. Indenização por perda de uma chance e sua adequada fundamentação. In: GUERRA, Ricardo; DINIZ, Giovanni Antonio, CHADI, Ricardo (org). Direito do Trabalho. 1. ed. Carderno 2. Belo Horizonte: Fumarc: 2015.

DIAS, José de Aguiar. Da responsabilidade Civil. 6. ed. v.1, Rio de Janeiro: Forense, 1979.

GOMES, Orlando. Direitos de personalidade. Revista de informação legislativa, v. 3. n. 11. p. 3948, set. 1966. Disponível em: https://www2.senado.leg.br/bdsf/item/id/180717. Acesso em: 06 mar. 2019.

MPMG. Drogaria Araújo deverá pagar multa de R\$ 7 milhões por capturar CPF dos consumidores. Belo Horizonte, 2018. Disponível em: https://www.mpmg.mp.br/comunicacao/noticias/drogariaaraujo-devera-pagar-multa-de-r-7-milhoes-por-capturar-cpf-dos-consumidores.htm. Acesso em: 28 ago. 2020.

NAGEL, Thoms. Como é ser um morcego? (1974). Revista Abordagem Gestalt. Goiânia, v. 19, n. 1, p.109-115, jul. 2013. Disponível em http://pepsic.bvsalud.org/scielo.php ?script=sci_arttext\&pid=S1809-68672013000100014\&lng=pt\&nrm=iso . acessos em 07 fev. 2021.

NETO, Eugenio Facchini. Da responsabilidade civil no novo Código. Revista Jurídica Porto Alegre: Notadez. Ano 55, junho, nº 356, p. 38, 2007.

HOFMANN, E.; RÜSCH, M. Industry 4.0 and the current status as well as future prospects on logistics. Computers in Industry, v. 89, p. 23-34, 2017.

JABUR, Gilberto Haddad. Liberdade de pensamento e direito à vida privada: conflitos entre direitos da personalidade. São Paulo: Revista dos Tribunais, 2000.

LÔBO, Paulo. Direito Civil: obrigações. 7. ed. v.2. São Paulo: Saraiva Educação, 2019. 
PEREIRA, Caio Mário da Silva. Responsabilidade Civil. Atual. Gustavo Tepedino. 12. ed. rev., atual. e ampl Rio de Janeiro: Forense, 2018.

RODOTÀ, Stefano. A vida na sociedade da vigilância: a privacidade hoje. Rio de Janeiro: Renovar, 2008.

ROSENVALD, Nelson; FARIAS, Cristiano Chaves de. Curso de Direito Civil: contratos. 7. ed. rev. atual. Salvador: JusPodivm, 2017a.

ROSENVALD, Nelson; FARIAS, Cristiano Chaves de. Curso de Direito Civil: parte geral e LINDB. 15. Ed. rev., ampl. e atual. Salvador: JusPodivm, 2017b.

ROSENVALD, Nelson; FARIAS, Cristiano Chaves de; BRAGA NETTO, Felipe Peixoto. Responsabilidade Civil. 4. ed. rev. atual. Salvador: Juspodivm, 2017c.

RUGGIERO, Roberto. Instituições de direito civil. Trad. de Ary dos Santos, Antônio Chaves e Fábio Maria de Mattia. 3. ed. v.3. São Paulo: Saraiva, 1973.

SACOMANO, Jose Benedito; et. al. Indústria 4.0: conceitos e fundamentos. São Paulo: Blucher, 2018.

SANSEVERINO, Paulo de Tarso Vieira. Princípio da Reparação integral: indenização no Código Civil. São Paulo: Saraiva, 2011.

STOCO, Rui. Tratado de Responsabilidade Civil: doutrina e jurisprudência. 10. ed. rev. atual. e reform. São Paulo: Revista dos Tribunais, 2014.

STJ- Informativo $n^{\circ}$ 0513. Período: 6 de março de 2013. $3^{\text {a }}$ Turma-REsp 1.292.141-SP. Rel Min. Nancy Andrighi. Disponível em: https://scon.stj.jus.br/SCON/SearchBRS?b=INFJ\&tipo= informativo\&livre=@COD=\%270513\%27 Acesso em: 04 set 2020.

TJMG, TJMG utiliza inteligência artificial em julgamento virtual. Notícia. 2018. Disponível em: https://www.tjmg.jus.br/portal-tjmg/noticias/tjmg-utiliza-inteligencia-artificial-em-julgamentovirtual.htm\#.XOkNctRKjlU. Acesso em: 28 ago. 2020.

VENOSA, Silvio de Salvo. A Constituição de 1988 e o Direito Civil. In MORAES, Guilherme Peña de; et al. 30 anos da Constituição Federal e o direito brasileiro. Rio de Janeiro: Forense, 2018.

Como citar: CARDOSO, João Victor Gontijo. O dano moral in re ipsa e o tratamento indevido de dados sob o prisma dos julgados: REsp. 1.758.799/MG e ADI 6387 MC-REF. Revista IBERC, Belo Horizonte, v. 4, n. 1, p. 133-153, jan./abr. 2021. 